This copy is for your personal, non-commercial use only.

If you wish to distribute this article to others, you can order high-quality copies for your colleagues, clients, or customers by clicking here.

Permission to republish or repurpose articles or portions of articles can be obtained by following the guidelines here.

The following resources related to this article are available online at www.sciencemag.org (this information is current as of April 22, 2010):

Updated information and services, including high-resolution figures, can be found in the online version of this article at:

http://www.sciencemag.org/cgi/content/full/328/5977/490

Supporting Online Material can be found at:

http://www.sciencemag.org/cgi/content/full/science.1185078/DC1

This article cites 24 articles, 7 of which can be accessed for free:

http://www.sciencemag.org/cgi/content/full/328/5977/490\#otherarticles

This article appears in the following subject collections:

Atmospheric Science

http://www.sciencemag.org/cgi/collection/atmos 


\section{Onset of Convective Rainfall During Gradual Late Miocene Rise of the Central Andes}

\author{
Christopher ]. Poulsen, ${ }^{1 *}$ Todd A. Ehlers, ${ }^{1,2}$ Nadja Insel $^{1}$
}

A decrease in the ratio of ${ }^{18} \mathrm{O}$ to ${ }^{16} \mathrm{O}\left(\delta^{18} \mathrm{O}\right)$ of sedimentary carbonate from the Bolivian Altiplano has been interpreted to indicate rapid surface uplift of the late Miocene Andean plateau (AP). Here we report on paleoclimate simulations of Andean surface uplift with an atmospheric general circulation model (GCM) that tracks oxygen isotopes in vapor. The GCM predicts changes in atmospheric circulation and rainfall that influence AP isotopic source and amount effects. On eastern AP slopes, summer convective precipitation increases by up to 6 millimeters per day $(>500 \%)$ for plateau elevations that are greater than about 2000 meters. High precipitation rates enhance the isotope amount effect, leading to a decrease in precipitation $\delta^{18} 0$ at high elevations and an increase in $\delta^{18} 0$ lapse rate. Our results indicate that late Miocene $\delta^{18} 0$ depletion reflects initiation and intensification of convective rainfall.

$\mathrm{T}$ he South American Andes, stretching $7000 \mathrm{~km}$ from north to south with average elevations of $\sim 4 \mathrm{~km}$, formed mainly through crustal thickening associated with Cenozoic subduction and convergence between the Nazca Plate and the South American Plate. Despite extensive research on the tectonic and geodynamic evolution of the Andes, the details of the timing, rate, and style of Andean surface uplift remain controversial. Recent elevation reconstructions based on fossil-leaf morphologies (1), carbonate clumped-isotope thermometry (2), and carbonate oxygen isotopic compositions (3) suggest a rapid, recent rise of the central Andes by $\sim 2.5 \pm 1 \mathrm{~km}$ during the late Miocene. However, this interpretation has been challenged by geological evidence that indicates a more protracted surface uplift history since the late Eocene $[\sim 40$ million years ago (Ma)] (4-6).

The most compelling evidence for rapid rise of the Altiplano plateau is a 3- to 4-per mil (\%o) decrease in the the ratio of ${ }^{18} \mathrm{O}$ to ${ }^{16} \mathrm{O}\left(\delta^{18} \mathrm{O}\right)$ of ancient soil carbonate nodules between 10.3 and $6.8 \mathrm{Ma}(3,7)$. In contrast to other paleoaltimetry methods, oxygen isotope paleoaltimetry has been widely applied and is based on isotope fractionation processes that are well understood. Isotope paleoaltimetry typically uses sedimentary carbonate $\delta^{18} \mathrm{O}$ as a proxy for ancient meteoric $\delta^{18} \mathrm{O}$. In the absence of knowledge about past isotopic lapse rates, carbonate $\delta^{18} \mathrm{O}$ is related to surface elevation change using modern isotopic lapse rates. In the modern climate, elevation and meteoric/surface water $\delta^{18} \mathrm{O}$ are well correlated [correlation coefficient $\left(r^{2}\right)=0.80$ ] with a global lapse rate of $2.8 \% \mathrm{~km}^{-1}(10)$. The elevation$\delta^{18} \mathrm{O}$ relationship reflects Raleigh distillation of

${ }^{1}$ Department of Geological Sciences, University of Michigan, Ann Arbor, MI 48109, USA. 'Institut für Geowissenschaften, Universität Tübingen, 72074 Tübingen, Germany.

*To whom correspondence should be addressed. E-mail: poulsen@umich.edu the heavy isotope $\left({ }^{18} \mathrm{O}\right)$ through condensation and precipitation as air masses are adiabatically cooled (11).

Precipitation $\delta^{18} \mathrm{O}$ and isotopic lapse rates can be influenced by factors other than air temperature, including the water vapor source, mixing between air masses, and isotopic fractionation through mass-dependent processes (12). At low latitudes where convective instabilities trigger
Fig. 1. South American topography (A) and mean annual continental rainfall $\delta^{18} O(B)$ predicted by the GENESIS AGCM. (A) Modern topography used in the model simulations. Boxes indicate northern, central, and southern Andean domains discussed in the text, Table 1, and Fig. 4. NAP and SAP represent the northern and southern regions of the $\mathrm{AP}$ as discussed in the text. (B) Simulated amountweighted rainfall $\delta^{18} 0$. The large negative values $(<-14 \%$ o) over the Andes compare well with modern observations of meteoric $\delta^{18} \mathrm{O}$.

heavy rainfall, the $\delta^{18} \mathrm{O}$ of air masses is correlated to rainfall rates (isotopic amount effect). In these regions, the isotopic lapse rate can deviate substantially from the global average (13).

The Andes figure prominently in South American climate and precipitation. Along the eastern Andean plateau (AP), orographic lifting enhances summer convective cells, leading to high rainfall amounts $(14,15)$. In addition, the Andes block zonal atmospheric flow and intensify low-level flow and vapor transport via the South American low-level jet (SALLJ) (16-18). The large influence of the Andes on regional climate has led to speculation that surface uplift caused past climate changes that substantially complicate paleoaltimetry interpretations $(13,19)$.

We used an isotope-tracking atmospheric general circulation model (GCM) (GENESIS) to quantify the influence of Andean surface uplift on rainfall $\delta^{18} \mathrm{O}$. Results from three GCM experiments with prescriptions of Andean elevations corresponding to $100 \%$ (modern, MOD) and $50 \%$ (intermediate, INT) of modern elevations, as well as 250-m elevation (low, LOW), are described (Fig. 1A). All other boundary conditions are identical between the experiments and are prescribed at modern values. Rainfall amounts and intensity are highly seasonal over the central Andes, with $>70 \%$ of annual AP rainfall occurring in the austral summer. For this

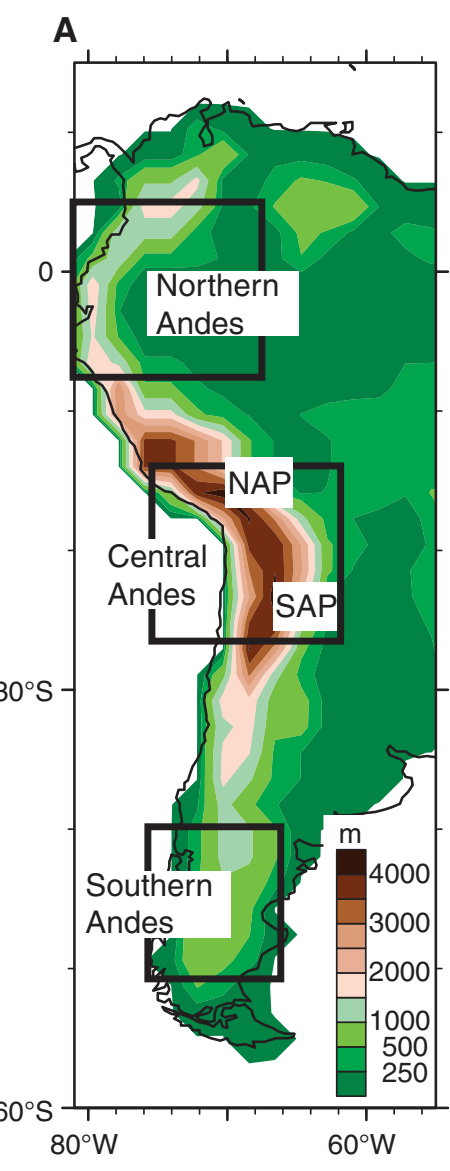

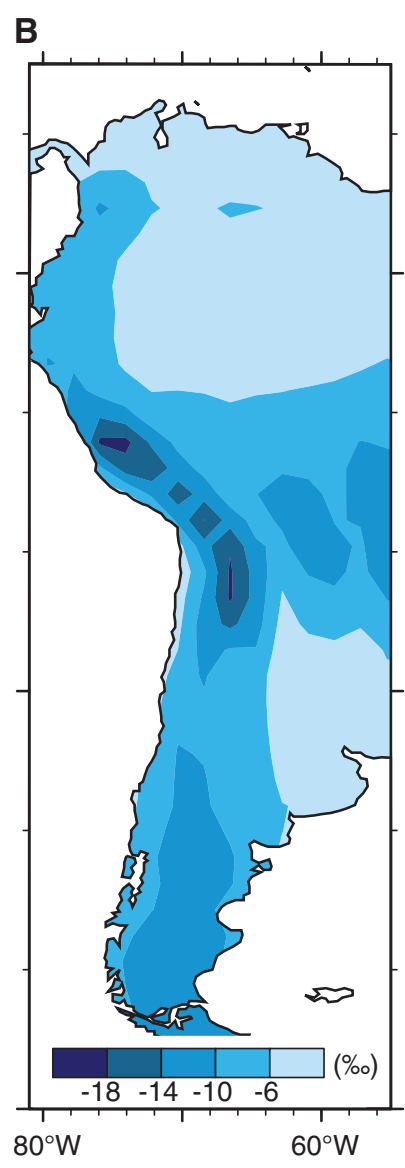


reason, we focus our analysis below on the December-January-February climatology.

GENESIS realistically simulates modern and paleo large-scale climate and circulation patterns as well as spatial variations in precipitation $\delta^{18} \mathrm{O}(20,21)$. Our simulated modern precipitation $\delta^{18} \mathrm{O}$ is in good agreement with sparse observations from the International Atomic Energy Agency (IAEA) Global Network of Isotopes in Precipitation $(22,23)$. As observed, the simulated mean annual rainfall $\delta^{18} \mathrm{O}$ is high $(-2$ to $-6 \%$ ) over the Amazon Basin because of isotopic fractionation through evapotranspiration, decreasing to the west over the Amazon Basin. The lowest rainfall $\delta^{18} \mathrm{O}$ occurs over the Bolivian Altiplano $(<-14 \%)$, which is due to the altitudinal and amount effects, and in southern South America $(<-10 \%)$, which is due to a latitudinal temperature effect (Fig. 1B). In agreement with modern observations (15), the source of precipitation over the Bolivian Altiplano is primarily water vapor transported via the SALLJ from the Amazon Basin. The main deficiency occurs over southern Brazil, where $\delta^{18} \mathrm{O}$ values are too low (by $\sim 4 \%$ ) because of not enough vapor transport from the southern Atlantic Ocean during the summer monsoon.

Simulated modern $\delta^{18} \mathrm{O}$ lapse rates in the Andes are also in good agreement with observations. In the northern and southern Andes (Fig. 1A), $\delta^{18} \mathrm{O}$ lapse rates are 2.58 and $3.36 \%$ $\mathrm{km}^{-1}$, respectively, and are consistent with observed values of 2 and $3 \% \mathrm{~km}^{-1}(24,25)$. In the model, the $\delta^{18} \mathrm{O}$ lapse rate over the central AP is $2.12 \% \mathrm{~km}^{-1}$. The $\delta^{18} \mathrm{O}$ lapse rate varies along the plateau and is $1.97 \% \mathrm{~km}^{-1}$ along an eastwest transect from the western Amazon Basin to the northern region of the plateau $\left(14^{\circ}\right.$ to $18^{\circ}$ $\mathrm{S}, 65^{\circ}$ to $\left.70^{\circ} \mathrm{W}\right)$. The predicted lapse rate for this transect is consistent with observed lapse rates that range from $2.31 \pm 0.32 \% \mathrm{~km}^{-1}$ to $1.46 \pm 0.67 \% \mathrm{~km}^{-1}$ for wet (1984) and dry (1983) years (26).

Andean surface uplift from $250 \mathrm{~m}$ to modern elevations substantially reduces precipitation $\delta^{18} \mathrm{O}$ over the Andes Mountains and the AP. Over the northern and southern Andes, $\delta^{18} \mathrm{O}$ decreases by 1 to $4 \%$. Over the central Andes, the decrease is greater, up to $\sim 10 \%$ (Fig. $2 \mathrm{~A}$ ), and correlates with changes in precipitation amount. However, the decrease in precipitation $\delta^{18} \mathrm{O}$ is not systematic with surface elevation increase. With an increase in the Andes from low to one-half modern elevations, rainfall $\delta^{18} \mathrm{O}$ decreases by $\sim 8 \%$ in the northern $\mathrm{AP}\left(\sim 10^{\circ}\right.$ to $\left.17^{\circ} \mathrm{S}\right)$ but increases by up to $\sim 4 \%$ on the southern AP $\left(\sim 20^{\circ}\right.$ to $\left.25^{\circ} \mathrm{S}\right)$ (Fig. $\left.2 \mathrm{~B}\right)$. With further uplift to modern heights, rainfall $\delta^{18} \mathrm{O}$ decreases by 1 to $3 \%$ over most of the Andes. In the southern AP, the rainfall $\delta^{18} \mathrm{O}$ decreases by 5 to $10 \%$ and corresponds with a significant increase in precipitation (Fig. 2C).
Our results indicate that changes in rainfall and rainfall $\delta^{18} \mathrm{O}$ are different for early (INTLOW) and late (MOD-INT) stage uplift. Thus, variations in $\delta^{18} \mathrm{O}$ preserved in sedimentary carbonates can only be partially explained by cooling associated with surface uplift. For example, if adiabatic cooling and associated changes in saturation vapor pressure were the predominant influence on precipitation $\delta^{18} \mathrm{O}$, then the $\delta^{18} \mathrm{O}$ decrease should be nearly systematic with an increase in surface elevation (fig. S1). Instead, changes in $\delta^{18} \mathrm{O}$ with surface uplift are linked to three major summertime circulation changes: (i) formation and strengthening of the SALLJ; (ii) southward shift and intensification of the Chaco Low, the subtropical high, and the midlatitude westerlies; and (iii) blocking of low-level flow to and from the Pacific Ocean (Fig. 3).

Surface uplift causes the SALLJ to intensify and shift westward toward the Andes (Fig. 3, B and $\mathrm{C}$, gray arrows). Intensification of the jet enhances low-level vapor transport from the Amazon Basin along the eastern flanks of the central Andes and into central South America. To the northeast of the Andes, the enhanced transport of isotopically enriched vapor from the Amazon leads to an increase in precipitation $\delta^{18} \mathrm{O}$ (Fig. 2B). The formation of the SALLJ with initial uplift leads to large $(>400 \%)$ increases in precipitation along the central Andes (Fig. 2B), predominantly $(>90 \%)$ due to convective activity

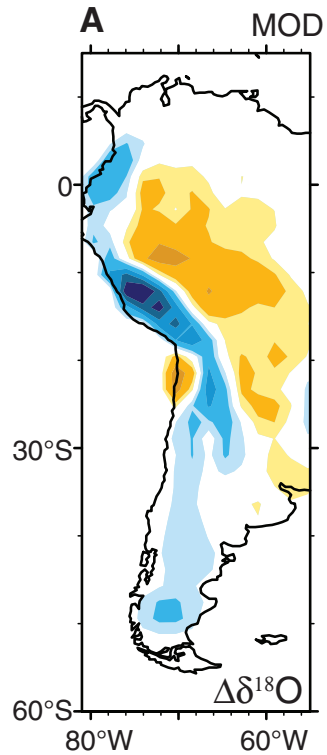

$80^{\circ} \mathrm{W}$

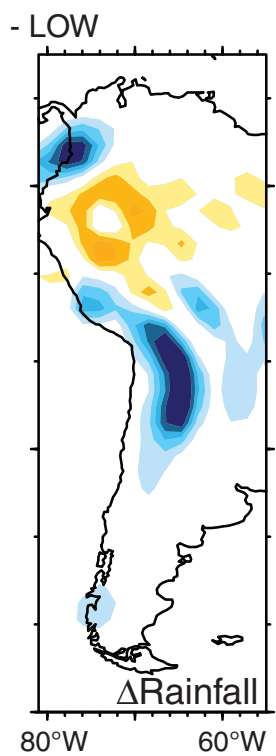

B

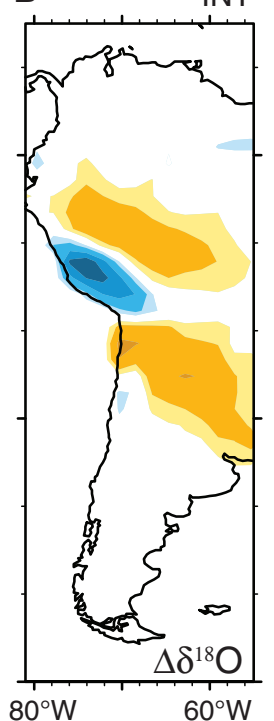

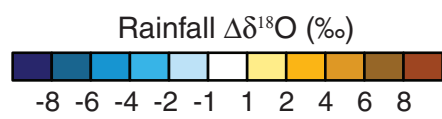

Fig. 2. Predicted change $(\Delta)$ in summer (December, January, and February) amount-weighted rainfall $\delta^{18} 0$ and rainfall rate due to Andean surface uplift. (A) Total simulated change in rainfall $\delta^{18} 0$ and rainfall rate due to Andean surface uplift. In (B), differences in rainfall $\delta^{18} 0$ and rate between the INT and LOW experiments are plotted, showing the influence of uplift to $50 \%$ of Andean elevations. In (C), differences in rainfall $\delta^{18} 0$ and rate between the MOD and INT experiments are shown. Convective precipitation accounts for nearly the

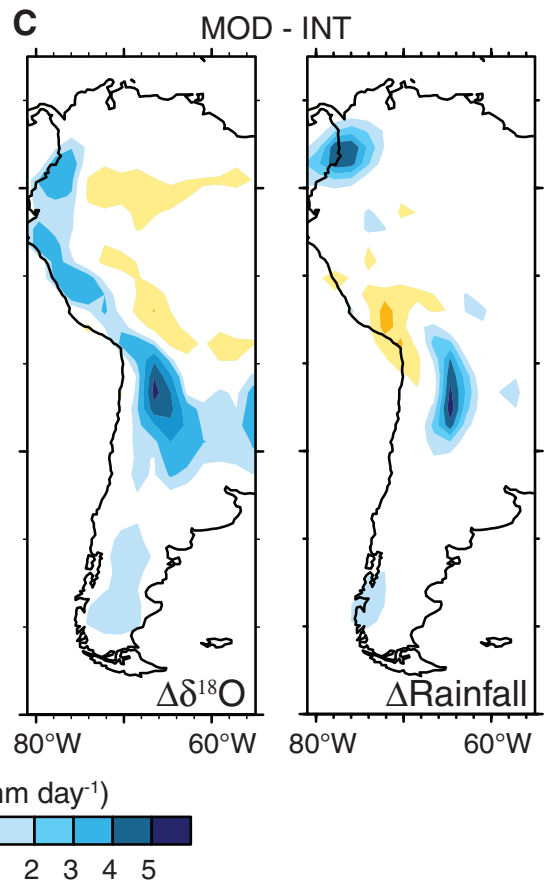

entire precipitation signal. The surface-uplift amounts represented by (B) and (C) are similar, yet the simulated isotopic responses are not. The differences in response are due to changes in atmospheric circulation and rainfall physics and indicate that factors other than surface elevation affect rainfall $\delta^{18} 0$. Also, there is a correspondence between increases in precipitation rate on and near the Altiplano and decreases in rainfall $\delta^{18} 0$. Predicted mean annual $\Delta \delta^{18} 0$ is qualitatively similar to summer $\Delta \delta^{18} \mathrm{O}$ (fig. S3). 
triggered by latent heat release as air masses converge on the plateau. Increased convective precipitation leads to a substantial $(>8 \%)$ decrease in rainfall $\delta^{18} \mathrm{O}$ in the northern central Andes $\left(\sim 10^{\circ}\right.$ to $17^{\circ} \mathrm{S}$ ) because of the amount effect (27).

Early uplift of the Andes also leads to southeastward displacement of the subtropical high away from the growing plateau and an associated southward shift in the midlatitude westerlies. The shift and strengthening of the subtropical high alters the balance of vapor sources in the southern central Andes (between $\sim 20^{\circ}$ and $25^{\circ} \mathrm{S}$ ) from primarily mid-latitude low $\delta^{18} \mathrm{O}$ regions in the LOW experiment to enhanced flow from the more $\delta^{18} \mathrm{O}$-enriched subtropical regions in the INT simulations (Fig. 3, B and $\mathrm{C}$ ). These changes in the low-level circulation with initial uplift result in an increase in vapor and rainfall $\delta^{18} \mathrm{O}$ in the southern central Andes, despite elevation gain (Fig. 2B).

The rise of the Andes to modern elevations of $\sim 4 \mathrm{~km}$ leads to blocking of low-level westerly flow from the South Pacific to the southern AP (Fig. 3A). At low elevations (INT and LOW), anticyclonic flow transports relatively dry cool air from the Pacific Ocean to the southern AP (Fig. 3, B and C). With increasing elevation (MOD), the convergence of warm, moist air from the Chaco region triggers convection and high convective rainfall along the eastern slopes of the central Andes $\left(\sim 20^{\circ}\right.$ to $\left.25^{\circ} \mathrm{S}\right)$, causing $\delta^{18} \mathrm{O}$ to decrease by $>8 \%$ (27) (Fig. 2C). Over the northern and southern Andes, surface uplift to modern elevations causes a decrease in rainfall $\delta^{18} \mathrm{O}$ of 1 to $4 \%$ (Fig. 2C), which is consistent with isotopic depletion through adiabatic cooling.

The changes in circulation and precipitation predicted by the GENESIS GCM, including the formation and strengthening of the SALLJ, shifting of the Chaco Low and westerlies, and intensification of convective precipitation, agree with higher-resolution climate simulations of South America $(17,18)$. Higher-resolution (60-km grid spacing) regional experiments also indicate that deep convection occurs at plateau heights that are $>50 \%$ of modern, or $\sim 2000 \mathrm{~m}$ (17). We verified this result with additional high-resolution $(25-\mathrm{km}$ grid spacing) regional simulations over central South America using the method of (17). These experiments confirm that precipitation on the eastern slopes of the central Andes increases abruptly when Andean elevations reach $\sim 70 \%$ of modern elevations (Fig. 4A)

Changes in isotopic source and amount effects with surface uplift also affect isotopic lapse rates. Over the AP, where the elevation increase in our experiments is greatest, the $\delta^{18} \mathrm{O}$ lapse rate is $1.1 \% \mathrm{~km}^{-1}$ in the INT experiment, which is one-half of the MOD lapse rate (Table 1). This result has implications for the AP uplift history, because oxygen isotope paleoaltimetry assumes that the modern $\delta^{18} \mathrm{O}$ lapse rate is representative of times when the mountains were lower.

To demonstrate the potential impact of convective rainfall intensification on paleoaltim-

Table 1. Mean annual precipitation $\delta^{18} 0$ lapse rates for northern, central, and southern Andean regions as shown in Fig. 1. Lapse rates are estimated by calculating a linear regression between amount-weighted annual precipitation $\delta^{18} 0$ and elevation. No estimates are made for the LOW experiment, which has no significant Andean topography by design. Correlation coefficients are shown in parentheses.

\begin{tabular}{lcc} 
Region & MOD $\left(\% \circ \mathrm{km}^{-\mathbf{1}}\right)$ & INT $\left(\% \circ \mathbf{k m}^{-\mathbf{1}}\right)$ \\
\hline Northern Andes & $3.07(-0.74)$ & $2.71(-0.54)$ \\
Central Andes & $2.12(-0.78)$ & $1.10(-0.24)$ \\
Southern Andes & $4.55(-0.59)$ & $4.57(-0.40)$ \\
\hline
\end{tabular}

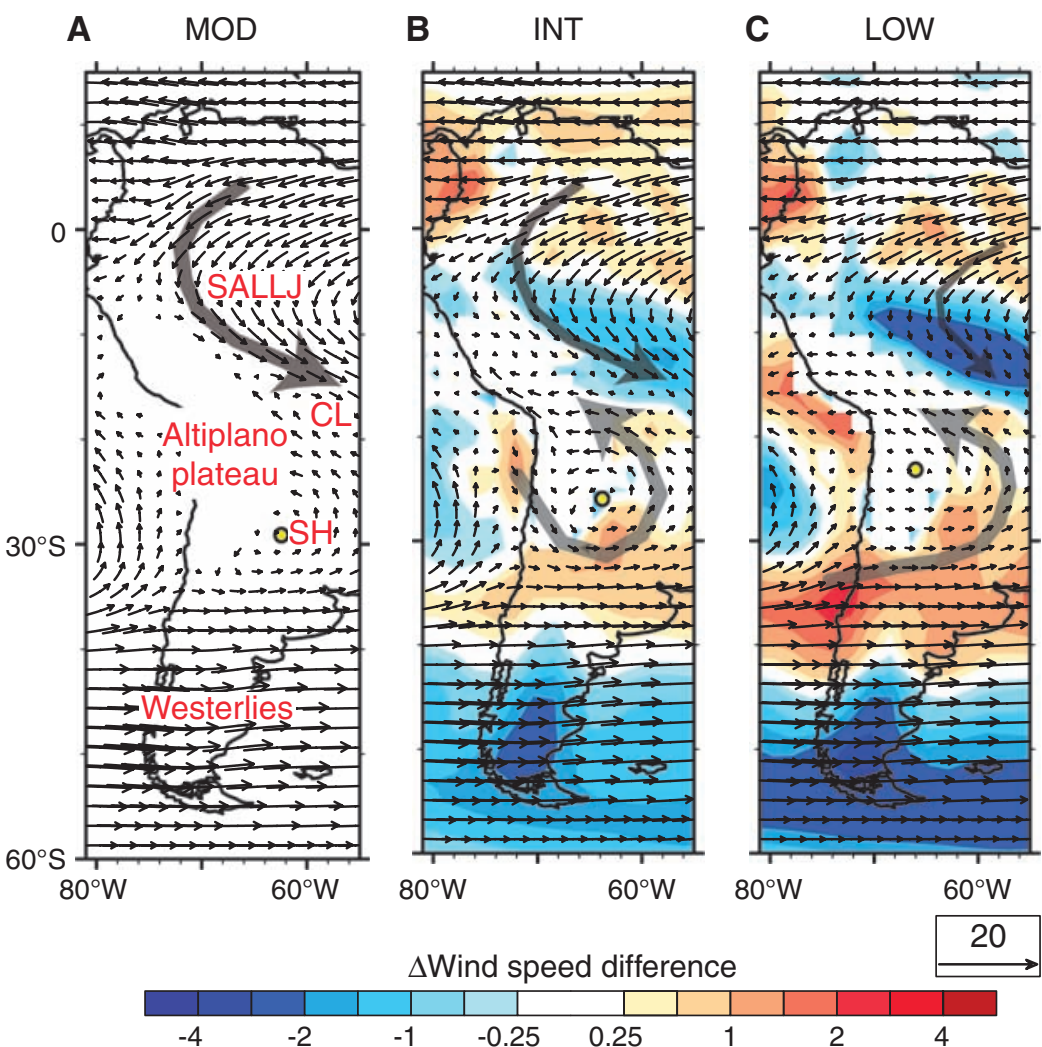

Fig. 3. Simulated summer low-level (800-mbar) circulation for the three uplift scenarios: (A) MOD (modern elevation), (B) INT (intermediate elevation), and (C) LOW (low elevation). Vectors are missing in (A) where the flow intersects high topography. The difference in $800-\mathrm{mb}$ wind speed (in meters per second) from the control (MOD) case (INT-MOD; LOW-MOD) is shaded; positive (red) values represent faster flow; negative (blue) values represent slower flow. Surface uplift modifies the low-level circulation. Most notably, the SALL] intensifies; the Chaco Low (CL), subtropical high (SH), and midlatitude westerlies migrate southward and become stronger. Yellow-filled circle indicates the center of the subtropical high; arrows indicate low-level circulation discussed in text.

etry estimates, we show a linear regression model of simulated central Andean rainfall $\delta^{18} \mathrm{O}$ and elevation for the INT and MOD experiments (Fig. 4B). At an elevation of $2000 \mathrm{~m}$, rainfall $\delta^{18} \mathrm{O}$ differs by $-1.7 \%$ between these experiments, a difference that is related only to climate change and mainly to isotopic depletion through rainout. If a $\delta^{18} \mathrm{O}$ signal of $-1.7 \%$ were found in the stratigraphic record, it would be interpreted with standard paleoaltimetry techniques based on modern $\delta^{18} \mathrm{O}$-elevation relationships as an elevation gain of $\sim 700 \mathrm{~m}$, when in fact no surface uplift had occurred. Extrapolation of the linear regression model for the INT experiment to higher elevations leads to larger rainfall $\delta^{18} \mathrm{O}$ differences between the MOD and INT experiments, a trend that is consistent with progressive rainout in the MOD case as air masses ascend the AP slopes. At an elevation of $3800 \mathrm{~m}$, which is the modern elevation of the late Miocene carbonate deposits used to estimate central Andean paleoaltimetry (3), rainfall $\delta^{18} \mathrm{O}$ differs by $-4.1 \%$, equaling the isotopic signal preserved in late Miocene deposits. Our point is not to argue against AP surface uplift - in fact, the onset of convection rainfall requires it - but to demonstrate that a 
Fig. 4. (A) Summer precipitation on the eastern AP as a function of elevation. The simulated precipitation rates are from five high-resolution (25$\mathrm{km}$ horizontal grid spacing) RegCM experiments with Andean heights varying as a percentage of modern height as in (17). (B) GENESIS precipitation $\delta^{18} 0$ versus elevation in the central Andes. Symbols represent annual average amount-weighted precipitation $\delta^{18} 0$ from individual grid points within a central Andes domain (Fig. 1, center). Values are from the MOD (blue) and INT (red) experiments. In agreement with observations, the model simulates a decrease in precipitation $\delta^{18} \mathrm{O}$ with elevation and interannual variability in precipitation $\delta^{18} 0$. The blue line shows the linear regression for the MOD and the red line shows it for the INT experiment. The linear regression line for the INT experiment is linearly extrapolated from 2000 to $4000 \mathrm{~m}$. There is an offset in both the intercept
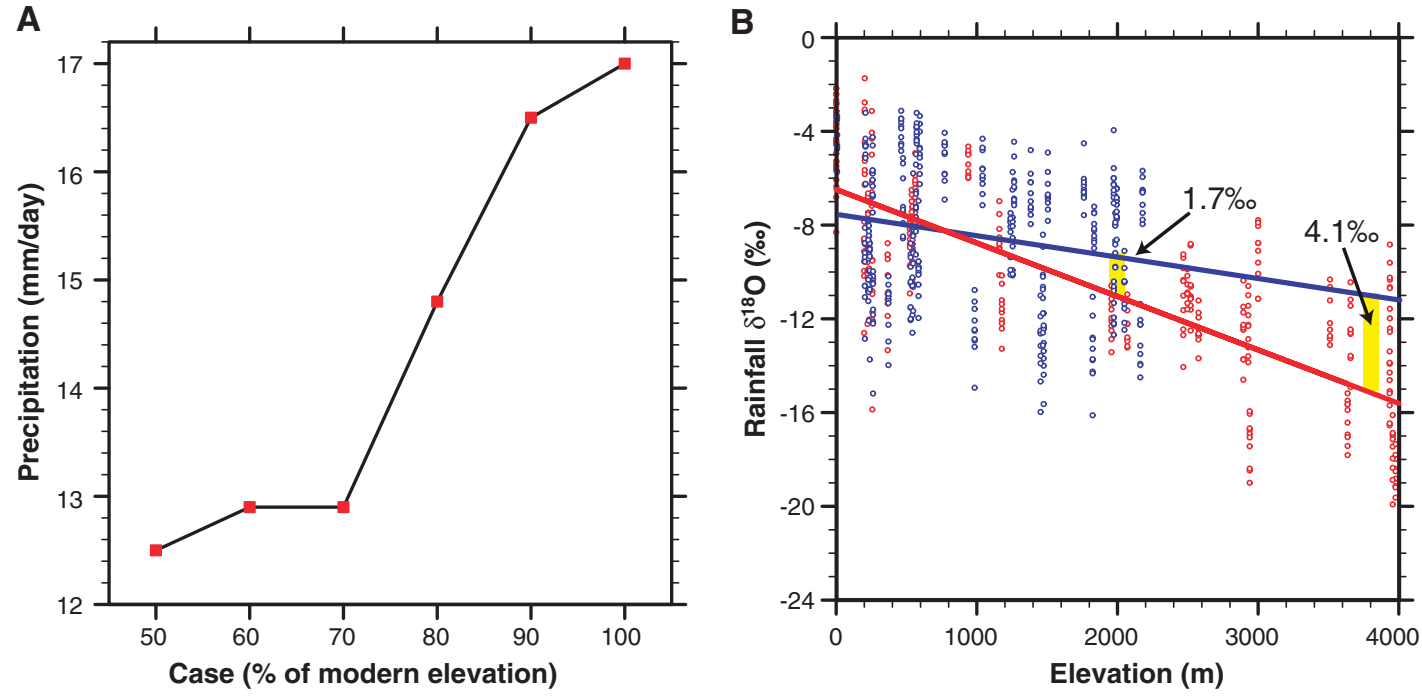

and slope of the regression line between experiments due to differences in the isotopic amount effect. Yellow bars highlight oxygen isotopic offsets of $\sim 1.7$ and $4.1 \%$ o between these experiments at 2000 and $3800 \mathrm{~m}$, respectively. substantial portion of the isotopic signal reflects climate change. In the northern and southern Andes, surface uplift has a minor influence on simulated rainfall rates and on isotopic lapse rates (Table 1)

Our GCM results resolve an inconsistency in the paleoaltimetry interpretation of carbonate $\delta^{18} \mathrm{O}$ data. Previous estimates using modern lapse rates suggest that paleoelevations were below sea level $(-700 \pm 1000 \mathrm{~m})$ before rapid uplift at $10.3 \mathrm{Ma}(2,3)$, which is at odds with geological evidence. Our results indicate that before the initiation of convective rainfall, the isotopic lapse rate would have been smaller; consequently, relatively large absolute $\delta^{18} \mathrm{O}$ values would have corresponded to higher elevations than today. In fact, simulated annual rainfall $\delta^{18} \mathrm{O}(-8.5 \%)$ for an AP region at $\sim 2000$ m elevation in the INT experiment is consistent with $\delta^{18} \mathrm{O}$ of water $(-6.9$ to $-10.5 \%$ ) derived from Miocene carbonates that were previously interpreted to have been deposited near sea level (fig. S2). Taken together, our results indicate that the late Miocene rapid decrease in $\delta^{18} \mathrm{O}$ results from changes in lowlevel winds and the onset of convective precipitation. The simulated onset of convective rainfall is supported by sedimentologic, paleontologic, and stable-isotope evidence for a shift from arid to humid conditions in the central Andes $(28-31)$.

\section{References and Notes}

1. K. Gregory-Wodzicki, Palaeogeogr. Palaeoclimatol. Palaeoecol. 180, 331 (2002).

2. P. Ghosh, C. N. Garzione, J. M. Eiler, Science 311, 511 (2006).

3. C. Garzione, P. Molnar, ]. Libarkin, B. Macfadden, Earth Planet. Sci. Lett. 241, 543 (2006).

4. A. J. Hartley, T. Sempere, G. Worner, Earth Planet. Sci. Lett. 259, 625 (2007)
5. J. B. Barnes, T. A. Ehlers, Earth Sci. Rev. 97, 105 (2009).

6. M. Mamani, G. Wörner, T. Sempere, Geol. Soc. Am. Bull. 122, 162 (2010).

7. Paleoaltimetry methods suffer from uncertainties in interpretation and analysis. Paleobotanical methods imply climate conditions that are consistent with a low-elevation $(1160 \pm 600 \mathrm{~m})$ Altiplano plateau (1). Yet climate predictions using leaf morphologies are based on modern empirical correlations with plant physiognomy that may not be appropriate for ancient plant communities or at high altitudes (8). Clumped-isotope thermometry of late Miocene Altiplano carbonates indicates that growth temperatures have decreased with time, a trend that is consistent with surface uplift $(2,9)$. However, growth temperatures for similarly aged deposits show large variability (up to $>20^{\circ} \mathrm{C}$ ) that is not completely understood (9) and may reflect processes other than adiabatic cooling.

8. E. Kowalski, Palaeogeogr. Palaeoclimatol. Palaeoecol. 188, 141 (2002).

9. J. Eiler, C. Garzione, P. Ghosh, Science 314, 760c (2006).

10. M. Poage, C. Chamberlain, Am. J. Sci. 301, (2001).

11. W. Dansgaard, Tellus 16, 436 (1964).

12. J. Gat, Annu. Rev. Earth Planet. Sci. 24, 225 (1996).

13. P. Blisniuk, L. Stern, Am. J. Sci. 305, 1033 (2005)

14. J. Lenters, K. Cook, J. Clim. 8, 2988 (1995).

15. R. Garreaud, Mon. Weather Rev. 127, 901 (1999).

16. C. Campetella, C. Vera, Geophys. Res. Lett. 29, 1826 (2002).

17. N. Insel, C. Poulsen, T. Ehlers, Clim. Dyn., published online 28 July 2009 (10.1007/s00382-009-0637-1).

18. P. Sepulchre, L. C. Sloan, F. Fluteau, in Amazonia, Landscape and Species, C. Hoorn, F. Wesselingth, Eds. (Wiley-Blackwell, Chicester, UK, 2010), pp. 211-222.

19. T. Ehlers, C. Poulsen, Earth Planet. Sci. Lett. 281, 238 (2009).

20. R. Mathieu et al., J. Geophys. Res. 107, 4037 (2002).

21. J. Zhou, C. Poulsen, D. Pollard, T. White, Paleoceanography 23, PA3223 (2008).

22. International Atomic Energy Agency-World Meteorological Organization (IAEA/WMO), Global network of isotopes in precipitation: The GNIP database. Available at http://isohis.iaea.org.
23. Supporting material is available on Science Online.

24. M. Garcia, F. Villalba, L. Araguas-Araguas, K. Rozanski, in Isotopes Techniques in the Study of Environmental Change (IAEA, Vienna, 1998), pp. 127-140.

25. L. Stern, P. Blisniuk, J. Geophys. Res. 107, (D23) 4667 (2002).

26. R. Gonfiantini, M. Roche, J. Olivry, J. Fontes, G. Zuppi, Chem. Geol. 181, 147 (2001).

27. The proportion of the rainfall $\delta^{18} 0$ change due to surface uplift can be estimated by multiplying the lapse rate by elevation change. Isotopic lapse rates in the central Andes are low when the Andes are one-half of their modern elevation (Table 1). Assuming a maximum elevation change of $2000 \mathrm{~m}$, approximately $2.2 \%$ of the $\delta^{18} 0$ signal can be attributed to adiabatic cooling through surface uplift. Isotopic lapse rates in the central Andes region are $2.1 \% \circ \mathrm{km}^{-1}$ in the modern case (Table 1). Assuming a maximum elevation change of $2000 \mathrm{~m}$, approximately $4.2 \%$ of the $\delta^{18} 0$ signal can be ascribed to adiabatic cooling through surface uplift.

28. K. Kleinert, M. Strecker, Bull. Geol. Soc. Am. 113, 728 (2001).

29. D. Starck, L. Anzotegui, J. S. Am. Earth Sci. 14, 763 (2001).

30. C. Uba, M. Strecker, A. Schmitt, Geology 35, 979 (2007)

31. A. Mulch, C. Uba, M. Strecker, R. Schoenberg, C. Chamberlain, Earth Planet. Sci. Lett. 290, 173 (2010)

32. D. Pollard and ]. Poulsen provided support with the GENESIS AGCM and data analyses, respectively. This work was funded by grants to C.J.P. and T.A.E. from NSF (EAR Awards 0738822 and 0907817) and the University of Michigan's Graham Environmental Sustainability Institute. C.J.P. also received support from the Alexander von Humboldt Foundation.

Supporting Online Material

www.sciencemag.org/cgi/content/full/science.1185078/DC1 Materials and Methods

Figs. $\mathrm{S} 1$ to $\mathrm{S3}$

References and Notes

24 November 2009; accepted 5 March 2010

Published online 1 April 2010;

10.1126/science. 1185078

Include this information when citing this paper. 